\title{
A INSUFICIÊNCIA DA PERÍCIA PSICOSSOCIAL E OS REFLEXOS NA SAÚDE DA CRIANÇA E DO ADOLESCENTE
}

\author{
Renata Salgado Leme \\ Universidade Santa Cecília (UniSanta), São Paulo. \\ renataleme@aasp.org.br \\ Alder Thiago Bastos \\ Universidade Santa Cecília (UniSanta), São Paulo. \\ thiago@advocaciabastos.adv.br
}

\begin{abstract}
RESUMO: Nas últimas décadas, com a transformação das sociedades, vem se consolidando a modificação da família e das relações familiares. Hoje, por exemplo, tornou-se usual ambos os genitores proverem o sustento da prole. Ademais, com o aumento dos divórcios também passou a ser comum a criação dos filhos em lares separados. Desse modo, o paradigma da guarda unilateral foi alterado para a guarda compartilhada, cabendo aos genitores a responsabilidade em gerir a vida dos filhos. Todavia, também surgiram novos conflitos que devem ser enfrentados pelos operadores do direito com o auxílio de uma equipe multidisciplinar, tendo como principal escopo a proteção do interesse da criança e do adolescente. Nesse contexto, é cada vez mais comum a constatação da prática de alienação parental, que deriva da implementação de falsas memórias ou acusações de negligências ou crimes contra a prole com o intuito de desqualificar um dos genitores, que implica gravosas consequências à saúde de crianças e adolescentes vítimas dessa prática, podendo gerar problemas psicológicos que refletem diretamente em casos de alcoolismo, uso de entorpecentes e, até mesmo, casos de suicídio. Assim, o presente artigo pretende investigar se a perícia psicossocial é suficiente para se identificar a prática de alienação parental.
\end{abstract}

PALAVRAS-CHAVE: Alienação parental. Perícia psicossocial. Saúde. Criança e Adolescente.

\section{The insufficiency of psychosocial expertise and reflections on child and adolescent health}

\begin{abstract}
In recent decades, with the transformation of societies, has been consolidating the modification of family and family relationships. Today, for example, it has become customary for both parents to provide for their offspring. In addition, with the increase of the divorces also became common the creation of the children in separated homes. Thus, the paradigm of unilateral guarding has been changed to shared custody, with parents having a responsibility to manage their children's lives. However, new conflicts have also arisen, which must be addressed by legal practitioners with the help of a multidisciplinary team, whose main purpose is to protect the interests of children and adolescents. In this context, it is increasingly common to observe the practice of parental alienation, which results from the implementation of false memories or accusations of negligence or crimes against offspring with the intention of disqualifying one of the parents, which entails serious consequences for the health of children and Adolescents victims of this practice, and can generate psychological problems that directly reflect in cases of alcoholism, use of narcotics and even cases of suicide. Thus, the present article intends to investigate if the psychosocial expertise is enough to identify the practice of parental alienation.
\end{abstract}

KEYWORDS: Parental alienation. Psychosocial expertise. Health. Child and Adolescent. 


\section{INTRODUÇÃO}

Considerando-se a significativa mudança dos contornos da família nos últimos tempos, ocorreram sensíveis alterações no regramento da contração de matrimônio e também na sua ruptura. Desse modo, atualmente é usual a dissolução da entidade familiar com a estipulação da guarda compartilhada ou unilateral, abandonando-se a concepção inflexível de guarda matriarcal que vigia anteriormente.

E, em muitas das vezes, as dissoluções matrimoniais geram feridas aos nubentes que, ante as cicatrizes, acabam por transferir aos seus filhos as mágoas e frustrações da união fracassada, buscando-se - nessas crianças e adolescentes - um aliado, uma vingança e/ou penalização do outro genitor tido como culpado pela ruptura.

Nesta senda, vendo-se que crianças e adolescentes são os principais prejudicados por esse luto no casamento fracassado, o cientista Richard Gardner, em 1985, nos Estados Unidos da América, classificou alguns critérios comuns dos malefícios gerados às vítimas dessa agressão e denominou de Síndrome da Alienação Parental (SAP).

Os estudos concluíram que as crianças e os adolescentes, vítimas de alienação parental são propensos a distúrbios psicológicos, tendem a utilizar entorpecentes e/ou álcool, a cometer suicídios, apresentam autoestima baixa e possuem dificuldades em manter relações estáveis quando alcançam a idade adulta, entre outros malefícios.

Diante da gravidade e do efeito devastador que causa na criança e adolescente vitimadas pela Alienação Parental, em agosto de 2010, foi promulgada a Lei $\mathrm{n}^{\text {o. }} 12.318$, ingressando no ordenamento jurídico brasileiro a proteção aos abusos tipificados, de forma exemplificativa, no artigo $2^{\circ}$, e também fazendo menção às sanções aplicadas aos alienantes, consoante se depreende do artigo $6^{\circ}$.

Transpôs-se, através de uma política pública de proteção à criança e ao adolescente, amenizar os males devastadores causados, bem como, evidentemente, trazer a punição ao transgressor da norma.

Contudo, estaria o Judiciário Pátrio preparado para absorver essa análise, considerando a multidisciplinaridade existente na identificação da alienação parental?

Dada a complexidade dos fatos em análise, evidentemente que - ao menos em cognição sumária - tem-se a percepção de que o magistrado não reúne condições de enfrentar o problema, transferindo o exame da questão para parte dos auxiliares da justiça, tais como peritos judiciais, subdivididos em psiquiatras, psicólogos e assistentes sociais, incumbindo a estes profissionais a árdua tarefa de identificar a alienação parental sob a ética positivada pela própria legislação protecionista, observando os mandamentos constitucionais de ampla defesa e contraditório, bem como os ditames determinados pela legislação que regula a matéria.

Nesse cenário, em que medida a alienação parental é identificada por meio da perícia psicossocial, considerando a legislação substantiva e adjetiva que rege a matéria?

Tendo em vista que se faz necessário responder às indagações introdutórias, este estudo tem por objetivo averiguar, por meio do método dedutivo, com base na análise de fontes bibliográficas, de julgados e de depoimentos de profissionais que militam na área (que são comumente nomeados por magistrados locados na área de família), se os meios trazidos para identificar a alienação parental são eficazes ou se a perícia psicossocial deveria ser aperfeiçoada para o reco- 
nhecimento da alienação parental gravosa à saúde mental e ao próprio desenvolvimento psicossocial das vítimas, uma vez que pode causar danos irreversíveis ou de difícil reparação na contínua exposição destas crianças e adolescentes às ações dos alienantes.

\section{ProteÇÃo da CRianÇA E do Adolescente}

\subsection{No âmbito internacional}

A Primeira Guerra Mundial trouxe o alarmante dado histórico de perda de 9 milhões de vidas (civis e militares) entre os idos de 1914 até 1918, criando-se grande impacto na devastação do continente Europeu no início do século XX, vivenciando a morte de civis, dentre eles crianças e adolescentes, sem falar na própria determinação que estes fossem submetidos a trabalhos braçais para custear a subsistência de suas respectivas famílias e a própria falta dos patriarcas que foram remetidos aos campos da guerra.

Com essa experiência estarrecedora e a população mundial à época preocupada com a própria continuidade da raça humana, sabendo-se que os recursos tecnológicos eram limitados, em 1924, segundo aponta a pesquisa de Angélica Barroso Bastos (2012, p. 25), confeccionou-se o "primeiro documento internacional sobre os Direitos da Criança".

Contudo, o mundo vivenciaria um novo impacto populacional com a morte de mais 47 milhões de pessoas (civis e militares) em decorrência da Segunda Guerra Mundial, entre os idos de 1939 até 1945, cujo resultado, após o declínio do Nazismo, foi a instauração da denominada Guerra Fria entre a então União Soviética e os Estados Unidos da América, com o risco constante de eclosão da Terceira Guerra Mundial, o que poderia implicar nova e impactante dizimação populacional.

Em meio a esta situação deflagrada com as guerras mundiais, morte de inocentes, inclusive de crianças e adolescentes, trabalho em condição análoga a escravo e o trabalho infantil, a população global buscava um documento jurídico que vinculasse todas as nações, cujo gerenciamento ficaria a cargo de uma organização internacional.

Nessa comoção social, nascera a Organização das Nações Unidas e, após curto período de tempo, fora criada a Declaração Universal dos Direitos Humanos, "preconizando em suas considerações iniciais a dignidade como pressuposto fundamental da liberdade, justiça e paz".

Como aponta Fabio Konder Comparato (2013, p. 245): “Logo no artigo 1丷, a Declaração proclama os três princípios axiológicos fundamentais em matéria de direitos humanos: a liberdade, a igualdade e a fraternidade".

Assim, houve previsão mínima substancial para adequar a própria dignidade perseguida pelas Nações Unidas e, com base nessa premissa, correlacionado com o artigo $1^{\circ}$, o artigo 25 , in verbis, estipulou que a saúde e o bem-estar deveriam ser prestigiados em igual condição com a preocupação dos interesses da infância, com guarida assistencial especial.

Artigo 25. 1. Toda a pessoa tem direito a um nível de vida suficiente para lhe assegurar e à sua família a saúde e o bem-estar, principalmente quanto à alimentação, ao vestuário, ao alojamento, à assistência médica e ainda quanto aos serviços sociais necessários, e tem direito à segurança no desemprego, na doença, na invalidez, na viuvez, na velhice ou noutros casos de perda de meios de subsistência por circunstâncias independentes da sua vontade. 2. A maternidade e a infância têm direito à 
ajuda e à assistência especiais. Todas as crianças, nascidas dentro ou fora do matrimônio, gozam da mesma proteção social.

A Convenção sobre os direitos das crianças integrada ao ordenamento jurídico de 1989 foi considerada um marco, pois, como afirmam Fúlvia Rosemberg e Carmem Lúcia Sussel Mariano (2010, p. 699):

\begin{abstract}
A Convenção de 1989, em relação às declarações internacionais anteriores, inovou não só por sua extensão, mas porque reconhece à criança (até os 18 anos) todos os direitos e todas as liberdades inscritas na Declaração dos Direitos Humanos. Ou seja, pela primeira vez, outorgou-se a crianças e adolescentes direitos de liberdade, até então reservados aos adultos. Porém, a Convenção de 1989 reconhece, também, a especificidade da criança, adotando concepção próxima à do preâmbulo da Declaração dos Direitos da Criança de 1959: "a criança, em razão de sua falta de maturidade física e intelectual, precisa de uma proteção especial e de cuidados especiais, especialmente de proteção jurídica apropriada antes e depois do nascimento".
\end{abstract}

Nada obstante, com as subdivisões de trabalho dentro da própria Organização das Nações Unidas, ficaram sob a responsabilidade da UNICEF os cuidados com as medidas protecionistas às crianças e adolescentes, conceituando-se quais os regramentos mínimos necessários para que o indivíduo nessa faixa etária tenha educação, saúde, cultura, lazer, sendo ressaltado o mínimo substancial para o desenvolvimento desejável desse indivíduo.

Portanto, com fundamento na Declaração Universal dos Direitos do Homem, é conclusivo ser possível a proteção especial da saúde da criança e do adolescente, cuja proteção social é um regramento objetivo, visando obviamente que crianças e adolescentes se tornem adultos mais seguros e conscientes do seu fundamental papel perante a nação.

\title{
2.2. No âmbito nacional
}

Em 12 de outubro de 1927, houve a promulgação do Decreto $\mathrm{n}^{\text {o. }}$ 17.943-A, com o primeiro Código de Menores Brasileiro, tutelando sobre menores órfãos ou que foram abandonados, trazendo a responsabilidade do cuidado pelo Estado, contudo não houve menção direta às proteções às crianças e aos adolescentes tais como são conhecidas nos dias atuais.

Nos anos de 1965, houve a promulgação da Lei ${ }^{0}$. 4.655, regulamentando a legitimidade para adoção, primeira evolução quanto à defesa de um direito dos infantes, contudo a proteção apenas relacionava as medidas para adoção e não fazia qualquer menção a outros direitos e garantias de um desenvolvimento sadio.

Nos anos de 1967 e 1968, houve a instauração de leis que visavam à reprimenda de menores infratores, contudo, até então, em que pese os organismos internacionais adotarem políticas de proteção às crianças e adolescentes, não havia qualquer legislação nacional que se igualasse a proteção objetivada pela Organização das Nações Unidas.

Com o advento da Constituição Federal de 1988, foram enaltecidos aspectos principiológicos e protecionistas aos seres humanos e, mais a fundo, também se levou em consideração a importância do meio ambiente, do trabalho, da educação, da saúde e da criança, como pilares do desenvolvimento, fundamento republicado que é a própria dignidade da pessoa humana.

Para tanto, previu como direitos sociais, o quanto subscrito no art. $6^{\circ}$ da Constituição Federal, em destaque:

Art. $6^{\circ}$ São direitos sociais a educação, a saúde, a alimentação, o trabalho, a moradia, o transporte, o lazer, a segurança, a previdência social, a proteção à maternidade e à 
infância, a assistência aos desamparados, na forma desta Constituição". E, especificamente, defende a saúde como um direito de todos e um dever estatal, tal como apresentado no artigo 196: "A saúde é direito de todos e dever do Estado, garantido mediante políticas sociais e econômicas que visem à redução do risco de doença e de outros agravos e ao acesso universal e igualitário às ações e serviços para sua promoção, proteção e recuperação.

Contudo, a leitura dos artigos não deve ser isolada, há a necessidade de aplicar a hermenêutica jurídica, fazendo uma interpretação sistemática, a fim de verificar que os aspectos saúde, educação, alimentação e proteção à infância estão repetidos no artigo 227 da Constituição Federal, in verbis, tamanha a sua importância:

Art. 227 É dever da família, da sociedade e do Estado assegurar à criança, ao adolescente e ao jovem, com absoluta prioridade, o direito à vida, à saúde, à alimentação, à educação, ao lazer, à profissionalização, à cultura, à dignidade, ao respeito, à liberdade e à convivência familiar e comunitária, além de colocá-los a salvo de toda forma de negligência, discriminação, exploração, violência, crueldade e opressão.

Como salienta José Afonso da Silva (2014, p. 868):

\begin{abstract}
A Constituição é minuciosa e redundante na previsão de direitos e situações subjetivos de vantagens das crianças, adolescentes e do jovem, especificando em relação a eles direitos já consignados para todos em geral, como os direitos previdenciários e trabalhistas, mas estatui importantes normas tutelares dos menores, especialmente dos órfãos e abandonados e dos dependentes de drogas e entorpecentes (art. 227, § $3^{\circ}$ ). Postula punição severa ao abuso, violência e exploração sexual da criança, do adolescente e do jovem.
\end{abstract}

Em consequência à própria ordem constitucional, foi promulgada a Lei n ${ }^{\text {o. }} 8.069$, de 1990 , estabelecendo os critérios de proteção à criança e ao adolescente, especificando, inclusive, sanções criminais a serem adotadas contra práticas de situações degradantes aos direitos protegidos, bem como reunindo toda a legislação que se refere à adoção e também às penalidades socioeducativas aos menores em apenas um estatuto, conhecido como Estatuto da Criança e do Adolescente.

Ainda que haja uma legislação especial e específica que tutela direitos e garantias das crianças e adolescentes, o Código Civil vigente, promulgado em 2002, também não ficou silente à positivação de direitos e garantias às crianças e adolescentes, regrando, de maneira menos específica, mas também importante.

Evidentemente que houve mudanças legislativas que alteraram o conceito de família e as percepções de responsabilidades, assim como verificamos hoje, contudo, em nenhuma dessas alterações mitigaram os direitos basilares em que sustenta a proteção da criança e do adolescente.

Com esse panorama inicial, é possível adentrar a temática de alienação parental, considerando-se especificamente a perícia adotada pelo Poder Judiciário averiguando se esta é suficiente para alcançar a proteção estipulada pela Lei $n^{\circ}$ 12.318/2010 e demais estatutos jurídicos que protegem a criança e o adolescente.

\title{
3. AlienaÇão parental
}

\subsection{Abordagem psiquiátrica}

Há tempos que a mente humana fascina os cientistas, justamente por isso buscam-se respostas sobre as capacidades do cérebro, posto que o ser humano distingue-se das demais espécies 
animais justamente porque raciocina e, em que pese não ser o animal mais forte, é considerado o mais inteligente em criar e utilizar ferramentas e mecanismos em benefício próprio.

Desta feita, domina a capacidade de fantasiar situações, de relatar com precisão falsas memórias e, de certa maneira, apresentar como verdadeira a falsa percepção de uma realidade, o que já foi referendado, de maneira sutil, por estudos de Buda, Confúcio e Sólon, no século VI a.C.

Contudo, a psicologia, como conhecida hoje, é derivada dos estudos de Sigmund Freud. Ao assentar suas duas teorias, Histeria e Complexo de Édipo, Freud já considerava a implementação de falsas lembranças na infância e que elas tinham sérias repercussões na vida adulta e, ainda que seus relatos fossem fidedignos, estes poderiam ser fantasiosos, conforme anotado por Viviane Malagodi Ciambelli (2012, p. 70). ${ }^{1}$

Não obstante, a imaginação em crianças é mais aflorada, elas são capazes de relatar, com riqueza de detalhes, situações inimagináveis que não são corroboradas com aspectos científicos, tornando-se mais fácil a manipulação de suas memórias, sentimentos e referências, sejam eles para amar ou odiar/repudiar outrem.

A situação não é diferente na fase da adolescência, já que fenômenos populares são idolatrados por pessoas nessa faixa etária, com relatos inimagináveis, propagado pela mídia, de forma menos fantasiosa e mais complacente com a realidade, mas sem perder a ilusão sob certa ótica.

Portanto, de plano, é possível assentar que a criança e o adolescente têm uma volatilidade em sentimentos e raciocínios, sendo facilmente manipulados por outras pessoas, de tal modo que, a própria legislação nacional e internacional preconiza a ausência de formação intelectual completa.

Nesta senda, a dicotomia da alienação parental entre patologia e danos causados foi estudada pelo psiquiatra Richard Gardner, junto ao Departamento de Psiquiatria Infantil da Faculdade de Medicina e Cirurgia da Universidade de Columbia, Nova York, Estados Unidos da América, trazendo a definição em 1985, segundo a qual Síndrome de Alienação Parental

[...] é um distúrbio da infância que aparece quase exclusivamente no contexto de disputas de custódia de crianças. Sua manifestação preliminar é a campanha denegritória contra um dos genitores, uma campanha feita pela própria criança e que não tenha nenhuma justificação. Resulta da combinação das instruções de um genitor (o que faz a 'lavagem cerebral, programação, doutrinação') e contribuições da própria criança para caluniar o genitor-alvo. Quando o abuso e/ou a negligência parentais verdadeiros estão presentes, a animosidade da criança pode ser justificada, e assim a explicação de Síndrome de Alienação Parental para a hostilidade da criança não é aplicável.

No entanto, é cabível uma consideração, a alienação parental é o meio utilizado pelo ofensor/alienante para afastar o convívio do outro genitor/alienado, mas a Síndrome da Alienação Parental é a patologia decorrente dos atos praticados, uma espécie de causa e consequência,

\footnotetext{
1 Viviane Malagodi Ciambelli (12,p.70) afirma, ainda, que a falsa percepção de lembranças implementadas na mente da criança é identifica danos estudos de Freud consignando que os relato sem Histeria "o fator traumático determinante dependia mais da 'fantasia' e da 'pulsão' do que da realidade da cena sexual" e complementa que, em decorrência deste estudo, abriu-se a perspectiva de uma nova teoria, denominada de Complexo de Édipo, apresentando que "a criança em determinada idade, geralmente por volta dos três anos, passa a estar sexualmente interessada no genitor do sexo oposto ao seu" e conclui que "seria a fonte das fantasias neuróticas dos adultos, relativas à sedução da infância, em que as fantasias representavam a manifestação de um desejo de gratificações dos interesses edipianos sem culpa".
} 
corroborando-se com a brilhante explicação de Priscila M. P. Corrêa da Fonseca (apud Alexandridis e Figueiredo, 2014, e-book, p.67):

\begin{abstract}
A síndrome da alienação parental não se confunde, portanto, com a mera alienação parental. Aquela geralmente é decorrente desta, ou seja, a alienação parental é o afastamento do filho dos genitores, provocado pelo outro, via de regra, o titular da custódia. A síndrome, por seu turno, diz respeito às seqüelas emocionais e comportamentais de que vem a padecer a criança vítima daquele alijamento. Assim, enquanto a síndrome refere-se à conduta do filho que se recusa terminantemente e obstinadamente a ter contato com um dos progenitores e que já sofre as mazelas oriundas daquele rompimento, a alienação parental relaciona-se com o processo desencadeado pelo progenitor que intenta arredar o outro genitor da vida do filho. Essa conduta quando ainda não dá lugar à instalação da síndrome - é reversível e permite - com o concurso de terapia e auxílio do Poder Judiciário - o restabelecimento das relações com o genitor preterido.
\end{abstract}

Contudo, a jurisprudência é uníssona ao afirmar que a alienação parental e/ou a síndrome tem como causa a ruptura do laço familiar, cujas relações afetivas são demasiadamente diferenciadas nos dias atuais, como explica Maria Berenice Dias (2010):

\begin{abstract}
Intensificações das estruturas de convivência familiar e a maior aproximação dos filhos com os pais e muitas vezes a ruptura da vida conjugal gera na mãe sentimento de abandono, de rejeição, de traição, surgindo uma tendência vingativa muito grande. Quando não consegue elaborar adequadamente o luto da separação, desencadeia um processo de destruição, de desmoralização, de descrédito do ex-cônjuge. Ao ver o interesse do pai em preservar a convivência com o filho, quer vingar-se, afastando este do genitor, esse fenômeno é denominado como Síndrome da Alienação Parental.
\end{abstract}

Em mesmo sentido, são os entendimentos de Ana Carolina Carpes Madaleno e Rolf Madaleno (2015), de Georgios Alexandridis e Fábio Vieira Figueiredo (2014) e de Flávio Tartuce (2012).

Por fim, também há que especificar que a Organização Mundial de Saúde, ao publicar a $11^{a}$ Revisar do Código Internacional de Doenças para Estatísticas de Mortalidade e Morbidade (CID 11), datado de junho de 2018, inseriu os atos alienativos como doença mental, trazendo a recente inovação ao tema.

Portanto, conclui-se não se tratar de um conceito jurídico na sua base, uma vez que advém de uma definição médica incorporada pelo direito, no entanto o que importa é que as medidas constitucionais protetivas, as legislações nacionais e internacionais trazem elementos significativos possibilitando que o direito se aproprie do termo da medicina e tenha imediata efetivação em razão do princípio do interesse da criança e do adolescente.

\title{
3.2. Abordagem Jurídica
}

Evidentemente que a própria Carta Magna faz menção expressa à defesa da saúde, como caráter universal, contudo, ao repetir o conceito no parágrafo subsequente, verifica-se que a ordem constitucional procurou enfatizar a necessidade de proteção aos direitos, enquanto o indivíduo é criança e/ou adolescente, observando os critérios estipulados pelos organismos internacionais.

Nada obstante, a alienação parental foi trazida para o nosso ordenamento jurídico através do Projeto de Lei no 4.053 , de 2008, de autoria do então Deputado Federal do Partido Social Cristão (PSC), Dr. Regis de Oliveira, ex-Desembargador do Tribunal de Justiça do Estado de São Paulo, em conjunto com o trabalho realizado pelo Juiz do Trabalho de São Paulo Dr. Elízio 
Luiz Peres, hoje titular da $41^{\text {a. }}$ Vara do Trabalho da Capital de São Paulo, ponderando a necessidade de medidas estatais para proteger crianças e adolescentes vítimas da alienação parental e da consolidação da síndrome, que é a patologia propriamente dita.

Nesta senda, depois dos ditames legislativos e com as devidas aprovações, foi submetida a legislação ao crivo presidencial, tendo vetado a alteração do art. 236, da Lei n ${ }^{0 .}$ 8.069/1990 (Estatuto da Criança e do Adolescente), não sancionando a criminalização das práticas de alienação parental, tal como contida no art. 10 do Projeto de Lei.

Concordamos com o posicionamento de Georgios Alexandridis e Fábio Vieira Figueiredo (2014, p. 123 e-book) ao afirmar que:

\begin{abstract}
Muito mais do que teor punitivo da sanção imposta pela prática do crime relativo à alienação parental, o objetivo da sua tipificação é visto muito mais como um meio coercitivo para afastar a prática da conduta, aliás, segundo a gravidade da conduta praticada, a maior ou a menor grau da alienação parental promovida, a tipificação também se mostra instrumento adequado na salvaguarda dos interesses do menor.
\end{abstract}

Todavia, é de mencionar, por oportuno, que tramita novamente na Câmara dos Deputados o Projeto de Lei 4.488/2016 que pretende alterar o artigo $3^{\circ}$, com a responsabilização do alienante na esfera criminal, podendo a pena do delito variar de 3 meses até 3 anos, com a possibilidade da conduta agravada, com acréscimo da pena em $1 / 3$, em uma política pública que visa criminalizar o ato de alienação parental, sem enfrentar sua problemática dentro do âmbito familiar e da própria conscientização.

Contudo, ao ser relatado na presidência da Comissão de Seguridade Social e Família, trouxe a Deputada Federal Shéridan (2017) opinou pela não criminalização da alienação parental, corroborando com seus argumentos um dado estatístico que representa 282 mil novos casos por ano, impondo uma linha de conscientização e não de punição em ultima ratio, segundo entendimento esposado no referido parecer.

Com a vigência da Lei a partir da data da sua publicação, estabeleceu-se o critério de alienação parental, conforme preceitua o art. $2^{\circ}$-abaixo transcrito:

Art. $2^{\circ}$ Considera-se ato de alienação parental a interferência na formação psicológica da criança ou do adolescente promovida ou induzida por um dos genitores, pelos avós ou pelos que tenham a criança ou adolescente sob a sua autoridade, guarda ou vigilância para que repudie genitor ou que cause prejuízo ao estabelecimento ou à manutenção de vínculos com este.

Parágrafo único. São formas exemplificativas de alienação parental, além dos atos assim declarados pelo juiz ou constatados por perícia, praticados diretamente ou com auxílio de terceiros:

I - realizar campanha de desqualificação da conduta do genitor no exercício da paternidade ou maternidade;

II - dificultar o exercício da autoridade parental;

III - dificultar contato de criança ou adolescente com genitor;

IV - dificultar o exercício do direito regulamentado de convivência familiar;

$\mathrm{V}$ - omitir deliberadamente a genitor informações pessoais relevantes sobre a criança ou adolescente, inclusive escolares, médicas e alterações de endereço;

VI - apresentar falsa denúncia contra genitor, contra familiares deste ou contra avós, para obstar ou dificultar a convivência deles com a criança ou adolescente;

VII - mudar o domicílio para local distante, sem justificativa, visando dificultar a convivência da criança ou adolescente com o outro genitor, com familiares deste ou com avós. 
Ao comentar o referido artigo, Ana Carolina Carpes Madaleno e Rolf Madaleno (2015, p. 172 e-book) apontam que:

O efeito perverso e ponto nevrálgico de caracterização da alienação parental decorre do ato inconsciente de rejeição da criança ao progenitor alienado, provocando irrecuperáveis prejuízos às relações de contato e de convivência do filho alienado com seu genitor visitante e cuja sadia comunicação constitui um imprescindível instrumento de manutenção e fomento da relação paterno-filial.

É importante mencionar que também tramita o Projeto de Lei no 7.569/2014, que pretende instituir programas permanentes de combate à alienação parental, dada a importância e a potencialidade da ofensa e os perversos efeitos que ela pode causar às crianças e aos adolescentes.

Há também a ação do Conselho Nacional de Justiça que visa combater a alienação parental, trazendo esclarecimentos sobre os fatos e as consequências na vida da criança, implementado, desde 2013, o projeto denominado de "Oficina de Pais e Filhos", cujo objetivo maior é trazer esclarecimento aos genitores e/ou quem exerce a função do poder familiar sobre a criança, mas não só, também se preocupa em trazer esclarecimentos aos próprios menores envolvidos no litígio judicial, havendo uma separação por faixa etária, direcionando-se cartilhas específicas para crianças e para adolescentes.

Portanto, nesse momento podemos dizer que o conceito da ciência médica foi transposto e passou a ser também uma definição jurídica, haja vista a importância protecionista, havendo diversos projetos que procuram alcançar uma maior proteção do interesse do infante vítima de alienação parental.

Contudo, o objeto central deste estudo é a verificação se os meios de identificação da alienação parental são suficientes para se desenhar uma pesquisa psicossocial capaz de averiguar se há a prática da alienação parental.

\section{AVAliaÇÃo PSicossocial e OS IMPACTOS NA SAÚdE DA CRI- ANÇA E DO ADOLESCENTE}

Assim, passamos a analisar a avaliação psicossocial que somente ocorre quando há um processo judicial em curso, motivado normalmente por denúncias de assédio sexual, moral ou negligências no tratamento da criança e/ou adolescente, fatos esses demasiadamente graves e bárbaros, que necessitam de intervenção imediata dos órgãos públicos fiscalizadores.

Nessa senda, portanto, a alienação parental não se inicia com a separação ou divórcio de fato, ela está ligada à própria construção do desfazimento do laço matrimonial que é externado, em última fase, com a tomada das medidas jurídicas cabíveis ao caso.

Como apontam Ana Carolina Carpes Madaleno e Rolf Madaleno (2015, p. 75, e-books):

A separação é uma dessas crises, mas possui um agravante de estender seus efeitos aos filhos, tanto no momento do divórcio quanto após, no tocante à criação da prole. Eivada de ressentimentos, essa ruptura do casal se inicia muito antes, não sendo o divórcio oficial a causa de conflito, e sim o pretérito distanciamento afetivo e físico, sendo o ato judicial somente uma gota d'água, em que o casal, ou um deles, se dá conta de que a partir de então, receberá maiores atribuições, passará a gerar a si próprio integralmente, sem o outro como seu cuidador. Portanto, quanto maior o grau de maturidade e de maturação do evento separação, em que cada membro do par mantém sua própria individualidade, em co-dependência do outro, melhores efeitos serão observados na família. 
A insuficiência da perícia psicossocial e os reflexos na saúde da criança e do adolescente

Assim, é cediço que o enfoque da avaliação psicossocial somente ocorre quando há um processo de alienação parental em desenvolvimento, motivando ao juízo, quando provocado, determinar uma avaliação, em até noventa dias, podendo ser prorrogada por justificativa circunstanciada.

No entanto, a atuação prática em processos judiciais dessa natureza, em que são disponibilizados todos os meios de defesa às partes (alienante/praticante e alienado/vítima), nos mostra que a situação é ambígua, pois, se de um lado se faz necessária a concessão de prazos processuais em atenção aos princípios e garantias constitucionais, por outro lado, prorrogar essa situação perpetua o dano causado à vítima de alienação parental.

Preocupado com tal situação, o legislador, ao inserir o artigo 5ํ. na Lei 12.318/2010, in verbis, destaca prazo e forma procedimental.

Art. $5^{\circ}$ Havendo indício da prática de ato de alienação parental, em ação autônoma ou incidental, o juiz, se necessário, determinará perícia psicológica ou biopsicossocial.

$\S 1^{\circ} \mathrm{O}$ laudo pericial terá base em ampla avaliação psicológica ou biopsicossocial, conforme o caso, compreendendo, inclusive, entrevista pessoal com as partes, exame de documentos dos autos, histórico do relacionamento do casal e da separação, cronologia de incidentes, avaliação da personalidade dos envolvidos e exame da forma como a criança ou adolescente se manifesta acerca de eventual acusação contra genitor.

$\S 2^{\circ}$ A perícia será realizada por profissional ou equipe multidisciplinar habilitados, exigido, em qualquer caso, aptidão comprovada por histórico profissional ou acadêmico para diagnosticar atos de alienação parental.

$\S 3^{\circ} \mathrm{O}$ perito ou equipe multidisciplinar designada para verificar a ocorrência de alienação parental terá prazo de 90 (noventa) dias para apresentação do laudo, prorrogável, exclusivamente por autorização judicial baseada em justificativa circunstanciada.

Na opinião de Georgios Alexandridis e Fábio Vieira Figueiredo (2014, p. 99, e-book):

Ainda, a perícia será realizada por profissional ou equipe multidisciplinar habilitados, exigida, em qualquer caso, aptidão comprovada por histórico profissional ou acadêmico para diagnosticar atos de alienação parental, ou seja, não é qualquer profissional com formação técnica na área de psicologia, psiquiatria ou em serviço social que tem aptidão para a avaliação adequada da existência da alienação parental; mostra-se necessário, dentre estes profissionais, a escolha daqueles cujo estudo e experiência se desenvolvam no campo da alienação parental, diante de suas especificidades e, para que de forma mais contundente possível, seja aferida a existência ou não da alienação parental.

Portanto, não somente os peritos psicossociais que devem ser treinados para a identificação da alienação parental, mas também se faz necessário que os juízes estejam abertos à discussão, havendo a integração do trabalho multidisciplinar entre os seus interlocutores interligando os trabalhos dos médicos, dos psicólogos, dos assistentes sociais e dos juristas (juízes, promotores e advogados), aplicando um trabalho multidisciplinar cujo enfoque principal é a busca da proteção das vítimas dessa situação (pais alienados ou as crianças e adolescentes).

E, nessa perspectiva, em que medida a alienação parental é identificada por meio da perícia psicossocial? Considerando o ordenamento jurídico substantivo e adjetivo aplicados à espécie, a perícia judicial é eficaz? Quais os meios? Estes meios são suficientes e adequados? Em que medida os meios deveriam ser aplicados para que haja um resultado eficaz e menos danoso aos envolvidos? 
Tentaremos responder estas perguntas, sem a mínima pretensão de esgotamento do tema, mas com o objetivo de contribuir e aperfeiçoar o instituto da perícia psicológica ou biopsicossocial.

\subsection{Dos profissionais atuantes}

É complexa a relação multidisciplinar dos profissionais que atuam para a identificação do problema de alienação parental, posto que, além dos operadores do direito (advogados, juízes e promotores), também devem ser enquadrados os peritos judiciais que são formados pelos profissionais de psicologia, medicina, bem como por assistentes sociais.

Grosso modo, médicos respondem pelo tratamento do corpo, inclusive com intervenção medicamentosa se o caso se fizer necessário, a fim de obter a cura do corpo do indivíduo, os psicólogos, por sua vez, têm por objetivo identificar e aconselhar traumas, medos e receios e, finalmente, os assistentes sociais trabalham em melhorias das condições de pessoas.

Com essa delimitação simplória das atuações dos profissionais que não tenham, necessariamente, formação jurídica, é de se destacar que o Conselho Federal de Psicologia, preocupado com o sigilo profissional, liberdade de atuação e defendendo os profissionais da área, editou a Resolução CFP n ${ }^{\circ}$ 008/2010, que, no seu artigo 10, Inciso I, prevê ser expressamente vetado ao psicólogo, que esteja atuando como psicoterapeuta das partes envolvidas no litígio, também assumir, concomitantemente, o papel de perito e assistente técnico.

Quanto ao veto referente ao perito, tal situação é prevista pela legislação processual vigente, mesmo após a alteração do Código de Processo Civil, mormente que o expert se torna impedido para auxiliar o juízo, ante seu envolvimento e vínculo pessoal com uma das partes interessadas, não trazendo a imparcialidade nas suas condutas profissionais, fato este que não traz qualquer espanto ao operador do direito.

Contudo, apesar de não haver impedimento legal, o Conselho Federal de Psicologia, a fim de preservar seus integrantes, veta ao profissional da psicologia atuar como assistente técnico quando já tem relação de psicanálise com uma das partes envolvidas no litígio ou de terceiros que desse processo fazem parte, pois, segundo a letra da lei, "perde o profissional a possibilidade de preservar a intimidade e a equidade de condições quando assume o cargo de assistente técnico e psicólogo pessoal da parte interessada e envolvida no litígio".

O Conselho Federal de Medicina também editou normas ético-profissionais aos seus inscritos e, nos termos dos artigos 91/98, que tratam dos auditores e peritos médicos, da Resolução CFM no 1.931/2009, não há quaisquer limitações para que o médico acumule as funções de médico pessoal da parte envolvida no litígio e de assistente técnico em processo judicial.

E, no mesmo sentido é a Lei no 8.662/93, que regulamenta o exercício profissional do assistente social, posto que não há veto para que exerça a função de assistente técnico quando conhece uma das partes envolvidas, e, quanto à perícia, por ser determinação legal do código processual, seu impedimento é inerente, apesar de ser incomum a indicação de assistente técnico para assumir essa função no processo judicial.

Não há descarte, no entanto, da atuação de outros profissionais da área da saúde ou da área social que possam integrar a equipe multidisciplinar na elaboração do laudo técnico para identificação da alienação parental, contudo é de assinalar que as cadeiras supramencionadas são as principais verificadas em processos judiciais dessa natureza. 


\subsection{Duração da perícia}

Superada essa abordagem relativa aos profissionais das cadeiras multidisciplinares, é de salientar que a perícia tem que ser realizada no prazo máximo de 90 (noventa) dias, cuja prorrogação está limitada à "justificativa circunstanciada”, o que autoriza a sua prorrogação.

Vale dizer que não é qualquer infortúnio que justifica a prorrogação da perícia, mas aquele que, porventura, cause impossibilidade de atuação profissional, sendo levadas ao crivo do juízo as circunstâncias e justificativas, cabendo ao magistrado que conduz o caso deferir ou indeferir a prorrogação eventualmente perquirida.

Contudo, em razão da própria limitação profissional, é certo que o profissional e periciando não têm contato ou conhecimento, não há uma construção de elo a fim de que, principalmente, a vítima da alienação parental possa se soltar e transpor os excessos do alienador.

Evidentemente que o expert buscará as ferramentas que lhe são oferecidas, contudo, é de salientar que a criança, a partir do $4^{\circ}$ ou $5^{\circ}$ ano de vida, passa a ser integrada à sociedade por meio da instituição escolar (creche, pré-escola ou ensino fundamental).

E é nesse ambiente que a criança demonstra as angústias e malefícios trazidos contra si, tal como aponta Viviane Malagodi Ciambelli (2012, p. 103), ao relatar um caso verídico tirado da Apelação no 990.10.240795-0, 1ª Câmara de Direito Criminal do Tribunal de Justiça do Estado de São Paulo, que consta o depoimento da Conselheira Tutelar: "A menor justificou os convites porque "uma vez que ela já tinha transado com o pai, transaria com qualquer um'” (fls. 194/199).

Portanto, considerando-se esses apontamentos, verifica-se que o trabalho técnico começa com relativo atraso, pois é evidente que o acesso aos dados escolares, aos professores e demais pessoas que interagem com criança e/ou adolescente depende de interferência direta do Poder Judiciário, e a limitação do prazo corre como um prejuízo capaz de prejudicar a perícia realizada.

\subsection{Principais ferramentas utilizadas pela perícia}

No artigo científico voltado à área da psicologia, Maria de Fátima Araújo (2007) traz uma série de elementos para diagnosticar e avaliar o indivíduo, dentre eles, podemos citar como os mais utilizados pelo profissional que atua frente ao Poder Judiciário é o "método de entrevistas", "jogo do rabisco", "a hora do jogo", "procedimento de desenho-estória".

Muitas dessas ferramentas são visualizadas no âmbito da perícia judicial nos setores especializados dos fóruns a fim de que haja a aproximação entre a vítima e o perito responsável pela análise fática dos casos de alienação parental e, evidentemente, de outros casos também demasiadamente graves que são levados diuturnamente ao conhecimento do Poder Judiciário.

Isto porque é cediço que não existe elo de paciente-psicólogo, bem como, muitas das vezes, crianças e/ou adolescentes vão à análise pericial pressionados, com uma carga emocional de medos, ódios incompreendidos e, geralmente, sentindo-se responsabilizados por discursos retóricos provenientes do genitor alienante, a fim de que a perícia contemple seus objetivos escusos.

Todavia, ao tratar especificamente da Alienação Parental e seus impactos nas decisões judiciais, Viviane Malagodi Ciambelli (2012, p. 113/114), citando Podevyn (2001), revela que:

A criança que sofreu realmente um abuso sempre lembra muito bem do que passou" o genitor alienado enxerga as consequências desastrosas ao passo que o alienador não 
os vê; existe uma patologia do genitor alienador no que tange ao comportamento psicopatológico "em outros setores de sua vida"; os alienantes sempre relatam que o outro genitor também praticou abusos contra si e finaliza ao descrever que o momento do abuso relatado começa muito antes da ruptura da união, mas a campanha de desmoralização provém depois da separação.

Conjugando-se a experiência doutrinária da psicologia clínica com a prática dos peritos judiciais, é possível concluir que o profissional que milita na área fica em desvantagem, posto que já parte de uma premissa de desconfiança e de desmotivação da criança e/ou adolescente, pelo discurso de responsabilização proferido pelo genitor alienante, com claro intuito de criar obstáculos na identificação da alienação parental.

Ainda que sejam raros os históricos de agressões físicas do alienante contra a criança ou adolescente vítima, seu objetivo não é aparentemente causar dano à integridade física do filho e, em muitas vezes, também não há consciência do dano psicológico, sua motivação está adstrita à penalização do genitor alienado.

Para Dayse Cesar Franco Bernardi (2010), a psicologia tem papel fundamental, posto que:

\begin{abstract}
O compromisso do psicólogo não fica restrito ao fornecimento de informações ao magistrado para a decisão do processo judicial, mas, em trabalhar todas as dimensões do caso, com vista à promoção e manutenção de uma política de garantia de direitos da infância e juventude. A intervenção psicológica nos casos depende, em grande parte, das relações estabelecidas com as políticas públicas e os programas sociais voltados para essa parcela da população, cujas características precisam ser conhecidas e contextualizadas pelo profissional. Seu trabalho não cessa com a emissão de um parecer psicológico sobre o caso, precisando, muitas vezes, reavaliar situações que se transformam ao longo do processo judicial.
\end{abstract}

Contudo, é importante dizer que os fatos jamais serão revelados de forma contundente, muito menos serão presenciados por testemunhas, cabendo aos auxiliares da justiça munir-se com o máximo de informações buscar junto ao colégio (se em idade escolar) informações da criança, identificar suas conversas com pessoas que estejam inseridas no seu convívio social, fazer uma análise a fundo da situação.

Lembre-se que há duas situações que podem causar danos à criança e/ou adolescente vítima da alienação parental: de um lado se as acusações do guardião contra o outro genitor são verdadeiras, o risco à integridade física e/ou psicológica é notório e, por outro lado, se falsas as acusações, a destruição do elo de afetividade entre vítima e genitor alienado também traz resultados catastróficos à vida da criança e/ou adolescente.

\title{
Conclusão
}

Com a reunião de todos os elementos trazidos no presente artigo, é possível afirmar que a perícia psicossocial é insuficiente para atingir os preceitos estabelecidos em legislação vigente.

Isto porque, são inúmeras as dificuldades enfrentadas para a averiguação multidisciplinar da alienação parental que vão desde a própria infraestrutura do Estado na realização dos procedimentos periciais, quanto à própria ausência de especialização técnica dos atores envolvidos para a identificação do problema e o modelo processual adversarial que impera no direito brasileiro.

A ineficiência do Estado em promover meios a fim de que a perícia seja realizada para a condução de uma verdadeira investigação de ocorrência de alienação parental é um problema inerente a própria falta de estrutura das unidades periciais alocadas no Poder Judiciário, porquanto referidas unidades acumulam um grande número de funções e de atendimentos, deixando 
de construir o vínculo mínimo e necessário para identificar os problemas envolvidos no litígio familiar, o que refletirá na própria decisão judicial quando da prolação da sentença judicial.

A falta de especialização dos profissionais que são alocados para tratar esse assunto (peritos, juízes, promotores, defensores públicos e advogados) também representa uma outra problemática que complementa a ineficiência do Estado, porquanto o desconhecimento sobre o assunto acaba sendo decisivo na definição do convívio familiar entre o menor vitimado pela alienação parental e seus genitores (alienante e alienado).

Por fim, há que destacar o modelo processual impera e se mantém enraizado no processo brasileiro, porquanto se transfere ao procedimento judicial a busca de um culpado pelo término da relação amorosa dos genitores, traduzindo-se em modelos combativos que não se preocupam com o bem-estar físico e mental das crianças e/ou adolescentes envolvidos nos litígios, apenas com o sentimento decorrente da própria relação fracassada.

Em linhas gerais, foi possível constatar que o princípio do melhor interesse do menor não é minimamente atendido com o modelo pericial estruturado e com a atuação combativa do modelo processual vigente, agravando-se a situação pela falta de especialização dos profissionais que lidam com a prática de alienações parentais, impondo risco a integridade física e psicológica das vítimas, trazendo consequências que são levadas para toda a vida dos envolvidos (crianças e/ou adolescentes vitimados e seus respectivos genitores).

Assim, impõe-se ao Estado implementar políticas públicas que estejam em sintonia com a nova realidade familiar e que sejam capazes de identificar a natureza dos novos conflitos familiares. E, não menos importante, a conscientização dos genitores das graves consequências da prática da alienação parental que repercutem na vida adulta de seus filhos alienados.

\section{REFERÊNCIAS}

ARAÚJO, Maria de Fátima. Estratégia de diagnóstico e avaliação psicológica. Periódico Eletrônico em Psicologia. Psicol. Teor. Prát. v.9 n.2. São Paulo, dez. 2007. Disponibilizado em http://pepsic.bvsalud.org/scielo.php?script=sci_arttext\&pid=S1516-36872007000200008.

Acesso em: 03 jun. 2017.

ALEXANDRIDIS, Georgios; FIGUEIREDO, Fábio Vieira. Alienação Parental, 2. ed. São Paulo: Saraiva, 2014.

BASTOS, Angélica Barroso. Diretos humanos das crianças e dos adolescentes: As contribuições do Estatuto da Criança e do Adolescente para a efetivação dos Direitos Humanos infanto-juvenis. Tese de mestrado da Universidade Federal de Minas Gerais, 2012.

BERNARDI, Dayse Cesar Franco. Avaliação Psicológica no âmbito das instituições judiciárias. Publicado no sítio da Associação dos Assistentes Sociais e Psicólogos do Tribunal de Justiça do Estado de São Paulo. Disponibilizado em http://www.aasptjsp.org.br/artigo/avaliaçãopsicológica-no-âmbito-das-instituições-judiciárias. Acesso em: 02 jun. 2017.

BRASIL. Comissão de Seguridade Social e Família. Parecer sobre o Anteprojeto n 4.488/2016 de Relatoria da Deputada Shéridan. Publicado em 05 set. 2017. Disponível em: http://www.camara.gov.br/proposicoesWeb/prop_mostrarintegra? codteor $=1594677 \&$ filename $=$ TramitacaoPRL+1+CSSF+\%3D\%3E+PL+4488/2016. Acesso em: 26 fev. 2018. 
BRASIL. Lei 12.318, de 26 de agosto de 2010. Dispõe sobre a alienação parental e altera o art. 236 da Lei 8.069 de 13 de julho de 1990. Brasília, DF, 2010. Disponível em: http:://www.planalto.gov.br/ccivil_03/_Ato2007-2010/2010/Lei/L12318.htm. Acesso em: 18 ago. 2017.

CASTRO. L. R. F. Disputa de guardas e visitas: no interesse dos pais ou dos filhos? Apud in CIAMBELLI, Viviane Malagodi. Impacto da alienação parental nas avaliações psicológicas e decisões judiciais. São Paulo: Iglu, 2012.

COMPARATO, Fabio Konder. A afirmação histórica dos direitos humanos. 8. ed. SP: Saraiva, 2013.

DIAS, Maria Berenice (Coord.). Incesto e alienação parental: Realidade que a justiça insiste em não ver. 2. ed. São Paulo: Revistas dos Tribunais, 2010.

DIAS, Maria Berenice. Manual de direito das famílias. 6. ed. São Paulo: Revistas dos Tribunais, 2010.

DIAS, Maria Berenice.Síndrome da alienação parental, o que é isso? Disponibilizado em: http://www.mariaberenice.com.br/manager/arq/(cod2_504)1_sindrome_da_alienacao__parental_o_que_e_isso.pdf. Acesso em: 09 mai. 2017.

ENTREVISTA de Eliane Nazareti, Elizio Peres entre outros convidados em 24/05/2012. No programa "Papo de mãe", disponibilizado em http://www.papodemae.com.br/2012/05/24/sobrea-lei-da-alienacao-parental-dr-elizio-perez/ Acesso em: 15 jun. 2017 .

FURLAN, Gabriel H. Z.; JUNIOR, Teófilo M. de A. L. Alienação Parental: 5 Anos da Lei 12.318/2010. REGRAD, UNIVEM/Marília-SP, v. 9, n. 1, p 163-184, agosto de 2016. Disponibilizado em: revista.univem.edu.br/REGRAD/article/view/1068/451. Acesso em: 02 jun. 2017.

FONSECA, Priscila M. P. Corrêa da. Síndrome de alienação parental. Revista Brasileira de Direito de Família, ano VIII, n. 40, fev.-mar. 2007. Disponibilizado em: http://priscilafonseca.com.br/sindrome-da-alienacao-parental-artigo-publicado-na-revista-do-cao-civel-no-15ministerio-publico-do-estado-do-para-jandez-2009-revista-ibdfam-ano-8-no-40-f/. Acesso em: 02 jun. 2017.

GARDNER, Richard A.. O DSM-IV tem equivalente para o diagnóstico de Síndrome de Alienação Parental (SAP)? - Traduzido por Rita Rafaeli. Disponibilizado em: http://www.alienacaoparental.com.br/textos-sobre-sap-1/o-dsm-iv-tem-equivalente. Acesso em: 09 maio 2017.

MADALENO, Ana Carolina Carpes; MADALENO, Rolf. Síndrome da Alienação Parental, 3. ed. rev. e atual. - Rio de Janeiro: Forense, 2015. - e-book

MONTEZUMA, Márcia Amaral. Síndrome de Alienação Parental: Diagnóstico médico ou jurídico? In: DIAS, Maria Berenice (Org.) Incesto e Alienação Parental de Acordo com a Lei 12.318/2010. 3. ed. São Paulo: Revista dos Tribunais, 2013.

OFICINA DE PAIS E FILHOS DE SÃO VICENTE. Projeto social chancelado pelo Conselho Nacional de Justiça desde 2013. Visita "in loco" realizada em 09 de agosto de 2018, Disponibilização de descrição do projeto, cartilhas e certificações.

ORGANIZAÇÃO MUNDIAL DE SAÚDE. 11ª Revisão do Código Internacional de Doenças para Estatísticas de Mortalidade e Morbidade - CID 11. Publicado em 18 jun. 2018. Disponível em: https://icd.who.int/. Acesso em: 31 jul. 2018.

PERES, Elizio Luiz. Constatava-se cegueira do Estado em relação à alienação parental Entrevista de 28/01/2011 ao IBDFAM - Instituto Brasileiro de Direito de Família. Disponibili- 
zado em: http://www.ibdfam.org.br/noticias/na-midia/4284/\%22Constatava-se+cegueira+do+Estado+em+relação+à+alienação+parental\%22+-+Entrevista +com+Elizio+Peres. Acesso em: 15 jun. 2017.

PIOVESAN, Flávia. Temas de Direitos Humanos: São Paulo: Saraiva, 2016.

PIOVESAN, Flávia. Direitos Humanos e direito constitucional: São Paulo: Saraiva, 2016.

ROSEMBERG, Fúlvia. MARIANO, Carmem Lúcia Sussel. A convenção internacional sobre os direitos da criança: debates e tensões. Cadernos de Pesquisa, v.40, n.141, set./dez. 2010http://www.scielo.br/pdf/cp/v40n141/v40n141a03.pdf- Acessoem 30 maio 2017.

SILVA, José Afonso da. Curso de Direito Constitucional Positivo. 38. ed. São Paulo: Malheiros - RT, 2014.

TARTUCE, Flávio; SIMÃO, José Fernando. Direito civil: direito de família. v.5. 7. ed. Rio de Janeiro: São Paulo: Método, 2012.

VENOSA, Silvio de Salvo. Direito civil: direito de família. 11. ed. São Paulo: Atlas, 2011. V. 6.

ZAPATA, Fabiana Botelho; FRASSETO, Flávio Américo; GOMES, Marcos Vinicius Manso Lopes. Ponto A Ponto - Direitos da Criança e do Adolescente - Col. Defensoria Pública. São Paulo: Saraiva, 2016.

Revista do Cao Civil - Ministério Público do Estado do Pará - Dezembro de 2009. Disponibilizado em: https://www2.mp.pa.gov.br/sistemas/gcsubsites/upload/25/REVISTA\%20DO\%20CAO\%20CIVEL\%2015(3).pdf. Acesso em: 02 jun. 2017.

Recebido em: 14 ago. 2018.

Aceito em: 28 jun. 2019. 